\title{
Ultrasound and computed tomography guided fine needle aspiration cytology in diagnosing intra-abdominal and intra-thoracic lesions
}

\author{
Parajuli $\mathrm{S}^{1}$, Tuladhar $\mathrm{A}^{1}$, Basnet $\mathrm{RB}^{2}$ \\ ${ }^{1}$ Department of Pathology, Kathmandu Model Hospital, Kathmandu, Nepal \\ ${ }^{2}$ Department of Pathology, National Academy of Medical Sciences, Kathmandu, Nepal
}

\section{Keywords: \\ Computed tomography; Deep-seated masses; \\ Fine needle aspiration; Ultrasound}

\begin{abstract}
Background: Ultrasonography and computed tomography guided fine needle aspiration cytology has an important role in diagnosing intraabdominal and intrathoracic mass lesions. It has an accuracy of 70-90\%, depending on the site under evaluation.

Materials and Methods: This retrospective study was done in the Department of Pathology, Kathmandu Model Hospital, between June 2006 and November 2010. The study included 53 abdominal and 47 thoracic masses. The cytological diagnosis was correlated with clinical and radiological data to arrive at a final diagnosis.

Results: Fine needle aspiration cytology was performed in various anatomic sites: liver (28 cases), pancreas ( 8 cases), lymph nodes ( 7 cases), ovary and gall bladder ( 3 cases each) and 2 cases each of gastrointestinal tract and omentum. Thoracic aspirations were done from the lung (44 cases) and mediastinum ( 3 cases). The most common malignancy encountered in the abdomen was hepatocellular carcinoma (12 cases). Non-small cell carcinoma was the most common diagnoses amongst the lung lesions (15 cases).
\end{abstract}

Conclusion: Ultrasonography and computed tomography guided fine needle aspiration cytology had a high sensitivity and specificity in diagnosing deep seated lesions.

\section{INTRODUCTION}

With the increased sophistication of radiologic imaging techniques, the sensitivity of detecting non-palpable, deepseated lesions has greatly improved. ${ }^{1}$

Single or multiple space occupying lesions demonstrated by Ultrasonography (USG), Computed tomography (CT) scan and Magnetic Resonant Imaging (MRI) constitute the main

Correspondence:

Dr. Sharmila Parajuli, $M D$

Department of Pathology, Model Hospital, Kathmandu, Nepal.

E-mail:drsharmi@hotmail.com indications for fine needle aspiration cytology (FNAC). ${ }^{2}$ Imaging techniques do not always distinguish between malignant and benign lesions morphologically. A confirmed tissue diagnosis is essential for both treatment and staging of cancers. ${ }^{3}$ FNAC is a well-established method of diagnosing neoplastic and inflammatory conditions of both the thorax and the abdomen.

The procedure's low complication rate is an additional advantage which allows FNAC to be performed as an out-patient procedure. It is also a suitable procedure when patients are debilitated or have multiple lesions. ${ }^{4}$ 
Complications that have been reported are hemorrhage, septicemia, biliary peritonitis, acute pancreatitis, and pneumothorax. Needle tract tumor implantation after FNAC has been reported but the survival outcome of these patients has not been studied in detail. ${ }^{5-6}$ Another concern is that preoperative FNAC may cause local tissue changes, which could render subsequent histological diagnosis difficult. ${ }^{7}$ The objective of this study was to evaluate the usefulness of USG and CT-guided FNAC in the diagnosis of intraabdominal and intra-thoracic lesions.

\section{MATERIALS AND METHODS}

This was a retrospective study done in the department of pathology, Kathmandu Model Hospital for a period of 4.5 years (June 2006 - November 2011). All patients who were clinically and radiologically diagnosed with intraabdominal and intra-thoracic lesions were included in the study. The aspirations were done by the radiologist or in conjunction with a pathologist. A total of 1304 aspirations were performed. One hundred and forty one (10.81\%) procedures were done under image-guidance. The aspirates were obtained from various anatomic sites such as the liver,

Table 1: Cytological diagnosis of intra-abdominal lesions

\begin{tabular}{|c|c|c|c|c|c|c|}
\hline & INFLAMMATORY & $\begin{array}{l}\text { No. of } \\
\text { Cases }\end{array}$ & $\%$ & NEOPLASTIC & $\begin{array}{l}\text { No. of } \\
\text { Cases }\end{array}$ & $\%$ \\
\hline \multirow[t]{8}{*}{ 1. LIVER (30 cases) } & Abscess & 4 & $7.55 \%$ & Hepatocellular carcinoma & 12 & $22.64 \%$ \\
\hline & & & & Metastatic adenocarcinoma & 4 & $7.55 \%$ \\
\hline & Hydatid cyst & 1 & $1.89 \%$ & Metastatic squamous cell carcinoma & 1 & $1.89 \%$ \\
\hline & & & & Poorly differentiated carcinoma & 2 & $3.77 \%$ \\
\hline & & & & Cholangiocarcinoma & 2 & $3.77 \%$ \\
\hline & & & & Malignant lymphoma & 2 & $3.77 \%$ \\
\hline & & & & Bile duct adenoma & 1 & $1.89 \%$ \\
\hline & & & & Focal nodular hyperplasia & 1 & $1.89 \%$ \\
\hline \multirow[t]{2}{*}{ 2. GALL BLADDER (3 cases) } & & & & Poorly differentiated carcinoma & 2 & $3.77 \%$ \\
\hline & & & & Adenosquamous carcinoma & 1 & $1.89 \%$ \\
\hline \multirow[t]{2}{*}{ 3. LYMPHNODE ( 7 cases) } & $\begin{array}{l}\text { Granulomatous lesion } \\
\text { suggestive of tuberculosis }\end{array}$ & 2 & $3.77 \%$ & Metastatic adenocarcinoma & 2 & $3.77 \%$ \\
\hline & & & & Non-Hodgkin's Lymphoma & 3 & $5.66 \%$ \\
\hline $\begin{array}{l}\text { 4. GASTROINTESTINAL } \\
\text { TRACT ( } 2 \text { cases })\end{array}$ & $\begin{array}{l}\text { Inflammatory- TB } \\
\text { abscess }\end{array}$ & 1 & $1.89 \%$ & Malignant tumour, adenocarcinoma & 1 & $1.89 \%$ \\
\hline \multirow[t]{2}{*}{ 5. OVARY ( 3 cases $)$} & & & & Serous cystadenocarcinoma & 2 & $3.77 \%$ \\
\hline & & & & Mucinous cystadenocarcinoma & 1 & $1.89 \%$ \\
\hline \multirow[t]{3}{*}{ 6. PANCREASE ( 6 cases) } & & & & Well-differentiated adenocarcinoma & 2 & $3.77 \%$ \\
\hline & & & & Poorly-differentiated adenocarcinoma & 3 & $5.66 \%$ \\
\hline & & & & Benign cystic neoplasm & 1 & $1.89 \%$ \\
\hline 7. OMENTUM ( 2 cases $)$ & & & & Metastatic adenocarcinoma & 2 & $3.77 \%$ \\
\hline Total & & 8 & $15.09 \%$ & & 45 & $84.91 \%$ \\
\hline
\end{tabular}

Table 2: Cytological diagnosis of intra-thoracic lesions

\begin{tabular}{|c|c|c|c|c|c|c|}
\hline & INFLAMMATORY & $\begin{array}{l}\text { No. of } \\
\text { Cases }\end{array}$ & $\%$ & NEOPLASTIC & $\begin{array}{l}\text { No. of } \\
\text { Cases }\end{array}$ & $\%$ \\
\hline \multirow[t]{7}{*}{ 1. LUNG (43 cases) } & Abscess & 3 & $6.38 \%$ & Non-small cell carcinoma & 15 & $31.91 \%$ \\
\hline & Tuberculosis & 4 & $8.51 \%$ & Small cell carcinoma & 7 & 14.89 \\
\hline & & & & Squamous cell carcinoma & 5 & $10.64 \%$ \\
\hline & & & & Poorly-differentiated carcinoma & 4 & $8.51 \%$ \\
\hline & & & & Bronchioloalveolar carcinoma & 2 & $4.26 \%$ \\
\hline & & & & Metastatic carcinoma & 2 & $4.26 \%$ \\
\hline & & & & Hemangioma & 1 & $2.13 \%$ \\
\hline 2.Para-hilar mass ( 1 case) & & & & Malignant lesion, Thymocarcinoma & 1 & $2.13 \%$ \\
\hline 3.Paratracheal LN ( 3 cases) & Tuberculosis & 2 & $4.26 \%$ & Non-Hodgkin's lymphoma & 1 & $2.13 \%$ \\
\hline Total & & 9 & $19.15 \%$ & & 38 & $80.85 \%$ \\
\hline
\end{tabular}


lungs, lymph nodes, gastrointestinal tract, pancreas, ovary, omentum, and gallbladder. Rare sites like the parahilar mass and paratracheal lymph node were also included. Forty-one of the 141 aspirations were excluded from the study as they were unsatisfactory as per our study criteria. The air dried and 95\% alcohol fixed smears were prepared for Giemsa and Papanicolaou stains, respectively. Clinical and radiological data were obtained from the medical records. The FNAC diagnosis was correlated with clinical and radiological information. The lesions were divided into inflammatory, benign or malignant categories. Acellular and inconclusive smears were excluded from the study. The original negative smears, smears with an unusual diagnoses or non-specified malignancies were reviewed by all the authors together to arrive at a final cytological diagnosis.

\section{RESULTS}

Out of 1304 FNACs done from June 2006 to November 2010,141 cases $(10.81 \%)$ were done under image guidance. The numbers of intra-thoracic and intra-abdominal lesions were 47 and 53 respectively, out of which, intra abdominal inflammatory lesion was 8 and intra thoracic 9, benign conditions were 3 and 1 respectively. Largest numbers of malignant cases were seen in intra-abdominal with 42 cases and 37 in intra-thoracic.

Largest numbers of malignant cases in both intra-abdominal and intra-thoracic lesions were seen in the age group of 6170 years.

The cytological diagnoses of intrathoracic and intraabdominal lesion are given in Table 1 and Table 2 respectively.

The most common malignancy encountered in abdomen was hepatocellular carcinoma (fig.1 A, B) followed by metastatic carcinoma in liver (fig. 2). Benign neoplasms included bile duct adenoma, focal nodular hyperplasia of liver and benign cystic neoplasm of liver.

The most common malignancy in the lung was Non-small cell carcinoma (fig. 3) followed by small cell carcinoma (fig. 4). There was 1 case of hemangioma of the lung.
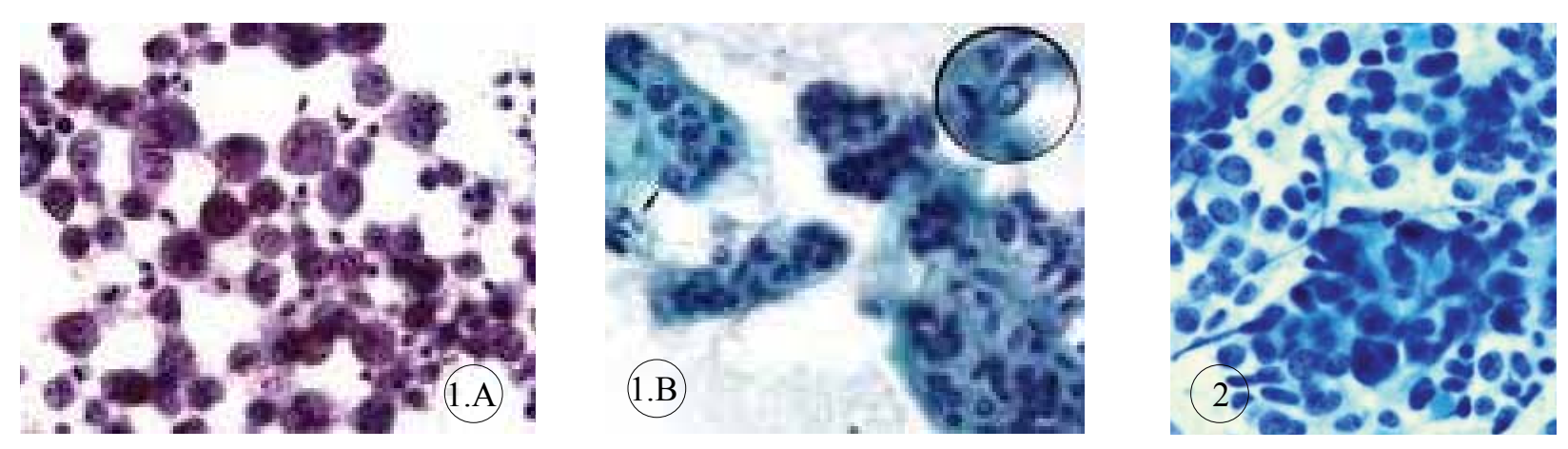

Figure 1: (A, B) FNAC smears of hepatocellular carcinoma inset showing intranuclear inclusion. (Papanicolaou stain, $X$ 40) Figure 2: FNAC smears of metastatic adenocarcinoma of liver (Papanicolaou stain, X40). The neoplastic cells are pleomorphic having fine granular chromatin and occasionally small or prominent nucleoli. Rare single benign hepatocytes are present in the background. (Papanicolaou stain, $X$ 40)
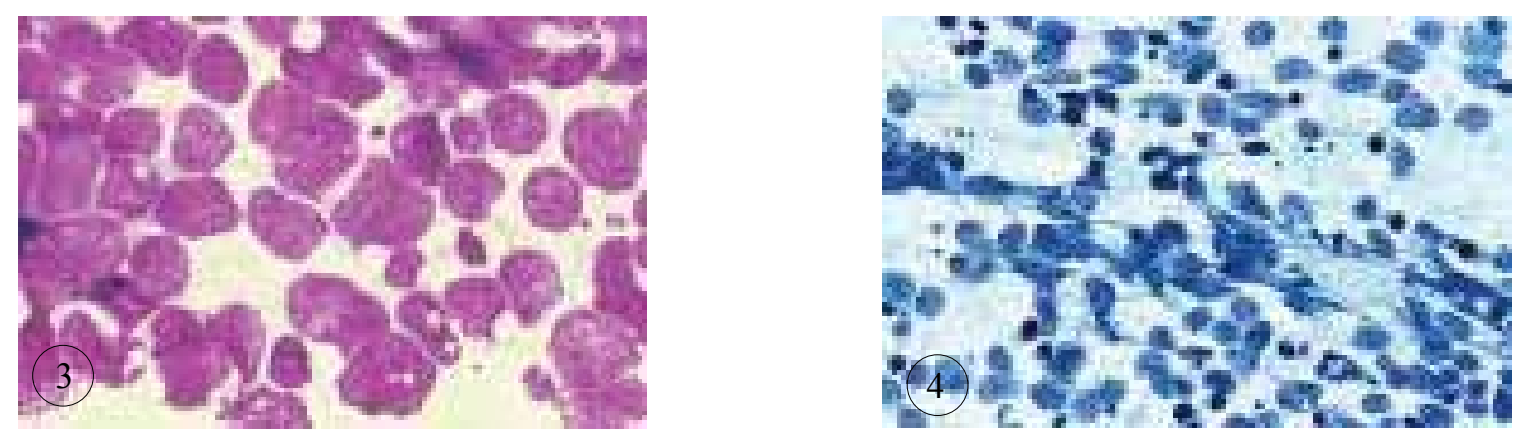

Figure 3: FNAC smears of non-small cell carcinoma of the lung (May Grunwald Giemsa Stain, X40)

Figure 4: FNAC smears of small cell carcinoma of the lung showing smearing artifacts (Papanicolaou Stain, X10) 


\section{DISCUSSION}

Image guided FNAC has facilitated easy collection of cellular material with greater accuracy. ${ }^{8}$ Previously inaccessible sites, like the intra-thoracic and intra-abdominal lesions can be safely sampled and are now routinely aspirated under image guidance to yield cellular material.

When the procedure is jointly done by a pathologist and the radiologist, the accuracy rate of obtaining a good sample is very high. The immediate assessment of the specimen by the on-site cytopathologist, along with further passes when necessary, improves the adequacy rate of the technique. ${ }^{9}$

Liver and lungs were the common sites for FNAC in this study as shown in table I and II which is comparable to the studies done by Sheikh et $\mathrm{al}^{10}$ and Adhikari RC. ${ }^{11}$ Liver was also the most common site of aspiration performed in the abdomen in a study done by $\mathrm{J}$ Nobrega et al. ${ }^{8}$

The age range of our patients was $19-83$ years. In the study by Tan $\mathrm{KB}$ et $\mathrm{al}^{12}$, the ages were between 11 and 82 years.

In our study, benign and malignant lesions were most common in the age group of 31-40 years and 61-70 years respectively. Mukherjee $\mathrm{S}$ et $\mathrm{al}^{13}$ found the maximum incidence of malignant lesion in the age group of 40-70 years.

The most common malignancy encountered in the abdomen was hepatocellular carcinoma of the liver, 12 cases $(22.6 \%)$ followed by metastatic carcinoma of liver, 7 cases $(13.2 \%)$. The incidence of carcinoma gallbladder in our study was 3 cases $(5.7 \%)$. In contrast to our findings, Zarger et al ${ }^{14}$ found the most common malignancy as carcinoma gallbladder followed by hepatocellular carcinoma (9.6\%). RC Adhikari ${ }^{11}$ found metastatic tumor of the liver as the most common malignancy encountered in the abdomen (38.4\%) followed by hepatocellular carcinoma $(24.8 \%)$. There were 8 cases $(15 \%)$ of pancreatic lesions in our study. Sheikh et $\mathrm{al}^{10}$ found 6 pancreatic lesions amongst the 120 cases.

Amongst the lung lesions; non-small cell carcinoma (15 cases) was the most common in our study, similar to the findings by Mukherjee $\mathrm{S}$ et $\mathrm{al}^{13}$.

Amongst the intra-abdominal lymph node aspirates in our study; out of the 7 cases, 2 cases were diagnosed as granulomatous lesion suggestive of tuberculosis and 5 cases were diagnosed as malignant lesions; 2 metastatic adenocarcinoma and 3 Non-Hodgkin's lymphoma. Porter $\mathrm{B}$ et $\mathrm{al}^{15}$ found $58.9 \%$ inflammatory lesions and $41.7 \%$ malignant lesions. Similar findings were reported by Das and Pant. ${ }^{16}$

In this study, FNAC has diagnosed not only benign and malignant neoplasm, but also non-neoplastic diseases like tuberculosis, hydatid cyst and abscess.

Twenty nine cases of the cytologically malignant cases were followed up for metastases, progression of radiological lesions or response to therapy. Of these, 5 cases had metastatic sites that were biopsied. Histopathologically, these correlated with primary cytological diagnosis.

We found that the review was especially important in the cases diagnosed as negative for malignancy. We also found that the review of slides by a second and third expert followed by a consensus diagnosis increased the accuracy.

Clinico-radiological parameters showed no false positives but 3 false negative results. Three cases that were clinicoradiologically diagnosed as benign lesion was diagnosed as malignant on image-guided FNAC 1 case of hepatocellular carcinoma, 1 case of Non-Hodgkin's Lymphoma of the intraabdominal lymph node and one case of small cell carcinoma lung. Tan $\mathrm{KB}$ et al $^{12}$ did clinico-radiological correlation with FNAC in 114 patients. Eight benign cases (7\%) proved to be malignant in clinical pathological follow-up.

Therefore, USG and CT- guided FNAC should be used as a routine procedure in the study of abdominal and thoracic lesions due to high sensitivity and specificity rate and very low complication rate. Barrios et al and others ${ }^{17-20}$ recommended that image guided FNAC should be used as routine procedure in the study of abdominal lesions and pulmonary lesions. ${ }^{21}$

\section{CONCLUSION}

In this study $84.9 \%$ and $80.4 \%$ of neoplastic lesions of the intra-abdominal and intra-thoracic were diagnosed by this simple out patient procedure with the lowest cost to the patient as compared to higher cost, morbidity and lengthy hospital stay in surgical biopsies.

\section{REFERENCES}

1. Reddy VB, Gattuso P, Abraham KP, Moncada R, Castell MJ. Computed tomography guided fine needle aspiration biopsy of deep seated lesions: a four year experience. Acta Cytol 1991;35:753-6.

2. Orell SR, Sterrett GF, Walters MN, Whitakar D. Manual and atlas of fine needle aspiration cytology. 4th ed; 2005. pp31-38.

3. Boiselle PM, Patz EF, Vining DJ, Weissleder R, Shepard JA, McLound TC. Imaging of mediastinal lymphnodes: CT, MR and FDGPET. Radiographics 1998;18:1061-9.

4. Pitman MB. Fine needle aspiration biopsy of the liver. Principal diagnostic challenges. Clin Lab Med 1998;18:483-506.

5. Roussel F, Dalion J, Benozio M. The risk of tumoral seedling in needle biopsies. Acta Cytol 1989;33:936-9.

6. Navarro F, Taourel P, Michel J et al. Diaphragmatic and subcutaneous seeding of hepatocellular carcinoma following fine needle aspiration biopsy. Liver 1998;18:251-4.

7. deSio I, Castellano L, Calandra M, Del Vecchio-Blanco C. Subcutaneous needle-tract seeding after fine needle aspiration biopsy 
of pancreatic liver metastasis. Eur J Ultrasound 2002;15:65-8.

8. Nobrega J, dos Santos G. Aspiration cytology with fine needle in the abdomen, retroperitoneum and pelvic cavity: a seven year experience of the Portuguese institute of oncology. Eur J Surg Oncol 1994;20:37-42.

9. Stewart CJ, Stewart IS. Immediate assessment of fine needle aspiration cytology of lung. J Clin Pathol 1996;49:839-43.

10. Sheikh M, Sawhney S, Dev P, al-saeed O, Behbehani A. Deepseated thoracic and abdominal masses: usefulness of ultrasound and computed tomography guidance in fine needle aspiration cytology diagnosis. Australas Radiol 2000;44:155-60.

11. Adhikari RC, Tuladhar A, Shrestha S, Sharma SK. Deep-seated thoracic and abdominal lesions: usefulness of ultrasound guided fine needle aspiration cytology, a 3 year experience. Nepal Medical Coll J 2010;12:20-5.

12. Tan KB, Thamboo TP, Wang SC, Nilsson B, Rajwanshi A, SaltoTellez M. Audit of transthoracic fine needle aspiration of the lung: cytological subclassification of bronchogenic carcinomas and diagnosis of tuberculosis. Singapore Med J 2002 ;43:570-5.

13. Mukherjee S, Bandyopadhyay G, Bhattacharya A, Ghosh R, Barui G, Karmakar R. Computed tomography-guided fine needle aspiration cytology of solitary pulmonary nodules suspected to be bronchogenic carcinoma: Experience of a general hospital. J Cytol 2010;27:8-11.
14. Zarger SA, Khuroo MS, Maharjan R, Shah P. Ultrasound guided FNAC of gallbladder masses. Radiology 1991;179:275-8.

15. Porter B, Karp W, Forsberg L. Percutaneous cytodiagnosis of abdominal masses by ultrasound guided fine needle aspiration biopsy. Acta Radiol Diagn 1981;22:663-8.

16. Das DK, Pant CS. Fine needle aspiration cytologic diagnosis of gastrointestinal tract lesions: a study of 78 cases. Acta Cytol 1994;38:723-9.

17. Barrios S, Hamana N, Quiros E. Cytology and biopsy by fine needle aspiration with ultrasound guidance in abdominal tumors. GEN 1989;43:155-60.

18. Stewart CJ, Coldewey J, Stewart IS. Comparison of fine needle aspiration cytology and needle core biopsy in the diagnosis of radiologically detected abdominal lesions. J Clin Pathol 2002;55:93-7.

19. Livraghi T, Sangalli G, Giordano F, Vettoric. Fine needle aspiration versus fine cutting needle and comparison between smear cytology, inclusion cytology and microhistology in abdominal lesions. Tumori 1988;74:361-4.

20. Lin BP, Chu JM, Rose RA. Ultrasound guided fine needle biopsy of the liver for cytology and histology. Australas Radiol 1991;35:33-7.

21. Diacon AH, Schuurmans MM, Theron J, Schubert PT, Wright CA, Bolliger CT. Safety and yield of ultrasound-assisted transthoracic biopsy performed by pulomonologists. Respiration 2004;71:519-22. 